\section{Prolegómenos}

\section{Derecho y Valores}

Prolegómenos. Derechos y Valores

ISSN: 0121-182X

derechos.valores@umng.edu.co

Universidad Militar Nueva Granada

Colombia

Bernal Guzmán, Ángela Patricia

LA FALTA DE AGOTAMIENTO DE RECURSOS INTERNOS COMO EXCEPCIÓN PRELIMINAR ANTE LA COMISIÓN INTERAMERICANA DE DERECHOS HUMANOS

Prolegómenos. Derechos y Valores, vol. XV, núm. 30, julio-diciembre, 2012, pp. 81-98

Universidad Militar Nueva Granada

Bogotá, Colombia

Disponible en: http://www.redalyc.org/articulo.oa?id=87625443005

- Cómo citar el artículo

- Número completo

- Más información del artículo

- Página de la revista en redalyc.org

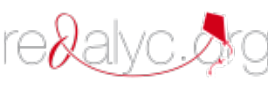

Sistema de Información Científica

Red de Revistas Científicas de América Latina, el Caribe, España y Portugal

Proyecto académico sin fines de lucro, desarrollado bajo la iniciativa de acceso abierto 


\title{
LA FALTA DE AGOTAMIENTO DE RECURSOS INTERNOS COMO EXCEPCIÓN PRELIMINAR ANTE LA COMISIÓN INTERAMERICANA DE DERECHOS HUMANOS
}

\author{
Ángela Patricia Bernal Guzmán*
}

Fecha de recibido: 3 de octubre de 2012

Fecha de aprobación:18 de noviembre de 2012

Artículo de Reflexión

Forma de citación: Bernal, A. P. (2012). La falta de agotamiento de recursos internos como excepción preliminar ante la Comisión Interamericana de Derechos Humanos. Revista Prolegómenos. Derechos y Valores, 15, 30, 81-98.

\section{Resumen}

El presente artículo analizará la excepción preliminar "Falta de agotamiento de recursos internos" como mecanismo de defensa estatal invocada ante la Comisión Interamericana de Derechos Humanos (CIDH). Se demostrarán las falencias o errores cometidos por los agentes estatales en la argumentación de la excepción, la cual ha sido superflua y equivoca al entregar argumentos definidos de forma previa por el órgano interamericano como improcedentes, en razón a su contradicción con los estándares internacionales de protección de los Derechos Humanos en el sistema regional.

\section{Palabras Clave}

Excepción preliminar, falta de agotamiento de recursos internos, Comisión Interamericana de Derechos Humanos, Estado.

\section{“NON-EXHAUSTION OF DOMESTIC REMEDIES” AS PRELIMINARY EXCEPTION BEFORE THE INTER-AMERICAN COMMISSION ON HUMAN RIGHTS}

\begin{abstract}
This article will analyze the preliminary exception "non-exhaustion of domestic remedies" as mechanism of State Defense invoked before the Inter-American Commission on Human Rights. It will demonstrate the failings or mistakes committed by the state agents'
\end{abstract}

Abogada Cum Laude Universidad Militar Nueva Granada, Joven Investigadora perteneciente al grupo de investigación de Derecho Público en el Proyecto "Comisión Interamericana de Derechos Humanos. Aspectos Procedimentales". 
argumentations of the exception, which has been superfluous and mistaken by delivering previously defined arguments by the Inter-American organ as unfounded because of their contradiction with the international standards of protection of the Human Rights in the regional system.

\title{
Keywords
}

Preliminary Exception, Non-Exhaustion of Domestic Remedies, Inter-American Commission of Human Rights, State.

\section{“FALTA DE ESGOTAMENTO DOS RECURSOS INTERNOS" COM EXCEÇÃO PRELIMINAR ANTE A COMISSÃO INTERAMERICANA DE DIREITOS HUMANOS}

\begin{abstract}
Resumo
Este artigo analisa a exceção preliminar "Falta de Esgotamento dos Recursos Internos" como um mecanismo de defesa invocado ante a Comissão Interamericana de Direitos Humanos. Ele vai demonstrar as falhas ou erros cometidos por agentes do Estado no argumento da exceção, o que é desnecessário e errado dar argumentos de pré-formas definidas pela American nacional como irrelevante porque sua contradição com as normas internacionais de proteção direitos humanos no sistema regional.
\end{abstract}

\section{Palavras-chaves}

Exceção preliminar, Falta de esgotamento dos recursos internos, Comissão Interamericana de Direitos Humanos, Estado.

\section{INTRODUCCIÓN}

El artículo se presenta como producto del proyecto de investigación que desarrolla la Universidad Militar Nueva Granada: "Comisión Interamericana de Derechos Humanos. Aspectos Procedimentales".

La investigación se desarrolló utilizando los métodos inductivo, descriptivo y analítico, partiendo del estudio de los informes de admisibilidad $e$ inadmisibilidad emitidos por la Comisión desde el año 2005 hasta el año 2011, con el fin de determinar el precedente del órgano interamericano respecto a la procedibilidad de la excepción falta de agotamiento de recursos internos, teniendo en cuenta la forma como los estados parte de la Convención han interpuesto la excepción.

Para ello,se elaboraron fichas jurisprudenciales y se identificaron nichos citacionales, como la determinación de espacios convencionales, para dar como resultado los requisitos y las exigencias de la Comisión para la procedencia de la excepción.

El artículo se desarrolla en tres partes; en la primera, denominada Cuestiones Previas, se explica el deber que poseen los peticionarios de agotar los recursos internos para poder acceder al Sistema Interamericano; la segunda, llamada Defensa Estatal, se exponen los errores cometidos por los Estados en desarrollo del argumento de 
defensa frente a la excepción falta de agotamiento de recursos internos durante el año 2011; y en la tercera, se exponen las conclusiones.

\section{CUESTIONES PREVIAS}

Del análisis de los informes de admisibilidad $e$ inadmisibilidad expedidos por la Comisión Interamericana de Derechos Humanos desde el 2005 hasta el 2011, respecto a la excepción preliminar falta de agotamiento de recursos internos, cabe resaltar lo siguiente:

En desarrollo del litigio interamericano, las partes en disputa adquieren ciertos deberes probatorios a saber:

\section{Los peticionarios y/o víctimas deben agotar los recursos internos antes de acudir a la jurisdicción internacional}

Ello, en razón a que la protección a los derechos humanos por parte del sistema interamericano se caracteriza por ser subsidiaria a la ofrecida por el derecho interno de cada uno de los estados parte de la Convención Americana(CIDH, 13 de noviembre de 2009, párr. 32; 29 de octubre de 2009, párr. 28; 4 de agosto de 2009, párr. 23 y 19 de marzo de 2009, párr. 35); es decir, la Comisión Interamericana podrá conocer de un caso de la vulneración a los derechos humanos cuando las autoridades estatales hayan tenido conocimiento del mismo; implica, entonces, el otorgamiento a los tribunales internos de la función de demostrar que su jurisdicción ofrece protección a los Derechos Humanos dentro de su territorio, por lo cual se ha establecido que:

(...) si la presunta víctima planteó la cuestión por alguna de las alternativas válidas y adecuadas según el ordenamiento jurídico interno y el Estado tuvo la oportunidad de remediar la cuestión en su jurisdicción, la finalidad de la norma internacional está cumplida(CIDH, 16 de octubre de 2008, párr. 40 y 24 de julio de 2008, párr. 42).
Es así como, reiteradamente, tanto la Comisión como la Corte han insistido en su condición de refuerzo y complemento dentro del sistema regional de protección de los derechos humanos, carácter consagrado en el artículo 46.1.a de la Convención. (CIDH, 4 de marzo de 2008, párr. 31).

En la gráfica núm. 1 se ilustra el nicho citacional referente a la subsidiariedad del Sistema Interamericano de Derechos Humanos:

\section{Enrique HermannPfister Frías y Lucrecia Pfister Frías Vs Argentina ${ }^{1}$}

Comunidad de la Oroya Vs Perú

\author{
I.V. Vs Bolivia
}

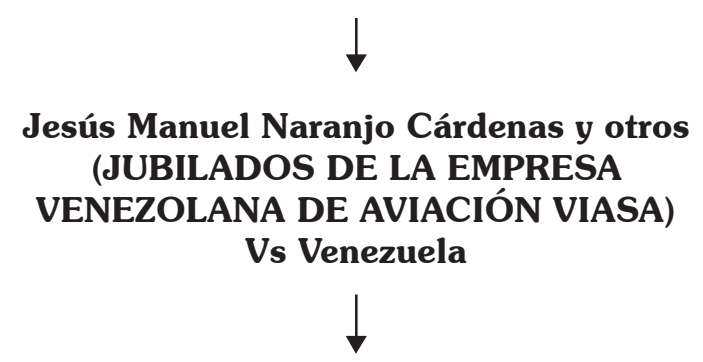

\section{Marcela Andrea Valdés Díaz Vs Chile}

Fuente: Elaboración propia con base en la CIDH (16 de marzo de 2010, párr. 31; 5 de agosto de 2009, párr. 55; 23 de julio de 2008, párr. 66 y 70; 13 de octubre de 2004, párr. 25 y 10 de octubre de 2003, párr. 40)

\section{El Estado que alega dicha excepción debe probar lo siguiente:}

a. Los recursos que debieron ser interpuestos (CIDH, 21 de octubre de 2006, párr. 22 y 17 de enero de 2009, párr. 54).

\footnotetext{
1 Se presenta el nicho citacional del escenario convencional "Subsidiariedad del Sistema Interamericano de Derechos Humanos".
} 
b. Dichos recursos resultan adecuados (CIDH, 5 de marzo de 2008, párr. 68; 5 de marzo de 2008, párr. 45).

Obligación que deviene de lo preceptuado y acogido por cada uno de los Estados, pues deben proveer a sus habitantes de recursos adecuados y efectivos, siendo estos los únicos que deben ser agotados por parte de las víctimas.

Entregando la senda jurisprudencia desarrollada por la Comisión Interamericana, el significado del carácter "adecuado" que debe revestir el recurso dispuesto para la utilización de las víctimas en cada uno de los ordenamientos internos.

\title{
Héctor Fidel Cordero Bernal Vs Colombia ${ }^{2}$

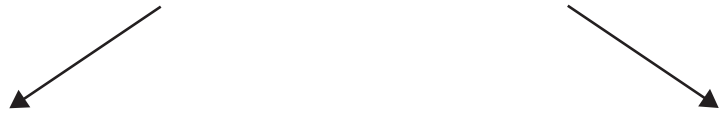

Homero Flor Freire Vs EcuadorMasacres Del Tibú Vs Colombia Marcela Alejandra Porco<smiles></smiles>

Vs Bolivia

\section{Miembros del Sindicato de Trabajadores Oficiales y Empleados Públicos de Antioquia Vs Colombia}

\author{
Victorio Spoltore Vs. Argentina
}

\section{Edgar Quiroga y Gildardo Fuentes Vs Colombia}

\author{
$\downarrow$ \\ María Isabel Véliz Franco Vs. Guatemala
}

Fuente: Elaboración propia con base en la CIDH (22 de julio de 2011, párr. 23; 15 de marzo de 2010, párr. 28;25 de julio de 2008, párr. 31; 15 de octubre de 2007, párr. 47; 21 de octubre de 2006, párr. 41; 18 de marzo de 2010, párr. 108; 4 de marzo de 2008, párr. 59)

En lo precedente, encontramos el fundamento del argumento que entregarán ambas partes en el curso del correspondiente procedimiento, pues, por un lado, los peticionarios tendrán que convencer a la $\mathrm{CIDH}$ de que los recursos disponibles dentro de la jurisdicción interna fueron agotados; o bien, se encuentran inmersos dentro de las excepciones a la falta de agotamiento de recursos internos (Articulo 46.2 $\mathrm{CADH}$ ).

2 Se presenta el nicho citacional del escenario convencional "Carácter Adecuado del recurso".
Dentro de la primera hipótesis antes planteada, los peticionarios y/o víctimas deben probar que la competencia subsidiaria ( $\mathrm{CIDH}, 22$ de julio de 2011, párr. 21) del Sistema Interamericano resulta del todo procedente, en razón de la ineficacia e inefectividad de los recursos por el Estado suministrados.

Cabe resaltar que aunque entre el 2005 y el2011 fue una constante las exigencias antes descritas al Estado, en los casos a continuación mencionados se analizaran los argumentos entregados por los Estados en desarrollo de su defensa. 


\section{DEFENSA ESTATAL}

\section{La Carga Probatoria Estatal}

\section{En el Caso Néstor Rolando López Vs Argen-} tina, en donde el Estado invoca la falta de agotamiento de recursos por parte de la víctima, pero no explica cuáles son los recursos adecuados y efectivos que debieron agotar ni la necesidad de recurrir en casación como recurso idóneo.

Resultando de ello que no cumplen su deber probatorio, siendo inconsistente cuando argumenta la existencia de recursos extraordinarios dentro de la jurisdicción interna, ya que esto resulta improcedente desde la óptica adoptada de forma precedente por la $\mathrm{CIDH}$, debido a que ya lo ha advertido esta organización: las víctimas no se encuentran obligadas a agotar los recursos que denoten característica de extraordinarios o especiales, en principio solo basta con dar a conocer a las autoridades la situación de vulneración (CIDH, 24 de marzo de 2011, párr. 139)33; lo que llevaría a interpretar tal situación de la siguiente forma: el Estado acepta de forma tácita que los peticionarios no agotaron los recursos, debido a la falta de consagración de los mismos dentro del ordenamiento jurídico interno, razón por la cual elabora una defensa con argumentos fútiles justificando, así, la inactividad de los peticionarios a nivel interno y confirmándole a la $\mathrm{CIDH}$ que las razones de hecho y de derecho expuestas por los mismos resultan del todo verídicas.

Algo parecido sucedió en el Caso Vicente Ariel Noguera Vs Paraguay, en razón a que el Estado, aunque alega una falta de impulso de la parte querellante, no especifica el porqué de esta afirmación, siendo Paraguay irresponsable,

3 (...) "el requisito de agotamiento de los recursos internos no significa que las presuntas víctimas tengan la obligación de agotar todos los recursos que tengan disponibles". En tal sentido, "si la presunta víctima planteó la cuestión por alguna de las alternativas válidas y adecuadas según el ordenamiento jurídico interno y el Estado tuvo la oportunidad de remediar la cuestión en su jurisdicción, la finalidad de la norma internacional está cumplida". pues no se puede afirmar hechos de los que no se tiene argumento, tan siquiera ligero y somero, incumpliendo nuevamente su carga probatoria.

Esto nos llevó a establecer que si bien los agentes estatales no se mostraron diligentes en demostrar los dos primeros elementos requeridos por la $\mathrm{CIDH}$, la situación no se torna diferente cuando el mismo organismo aumenta su deber probatorio.

Es este el momento para analizar los diferentes argumentos entregados por el Estado en virtud del desarrollo de su defensa estatal con respecto a la falta de agotamiento de los recursos internos:

\section{En el Caso Héctor Fidel Cordero Bernal Vs}

Perú, aunque el Estado alego que las presuntas víctimas no habrían agotado a nivel interno los recursos proporcionados, como lo eran la demanda laboral o acción constitucional (cumplimiento), no plantearon la idoneidad de las mismas, lo que indica que al Estado le hace falta mayor compromiso en la asunción de su defensa internacional, toda vez que no es claro por qué aun conociendo los requisitos o criterios exigidos por la $\mathrm{CIDH}$ para evaluar la procedibilidad de la excepción, no propenden por llegar a una explicación que pueda persuadir a este organismo de que efectivamente los recursos enunciados si resultaban apropiados para subsanar la transgresión invocada.

Dentro de la misma línea argumentativa, es procedente advertir que en el Caso Jahel Quiroga Carrillo Vs Colombia es novedoso el argumento estatal que reconoce el precedente establecido por la $\mathrm{CIDH}$, al afirmar que, dentro del Estado, pueden existir recursos internos distintos, frente a situaciones distintas, que generen infracciones también distintas a la Convención Americana, y entienden que pueden existir recursos distintos frente a cada uno de los derechos presuntamente vulnerados.

Por ello, en desarrollo de su defensa, adujo que los peticionarios no han cumplido con el requisito del previo agotamiento de los recursos internos y no es posible señalar la inexistencia o 
ineficacia de los recursos disponibles, puesto que las violaciones alegadas tienen preestablecido un recurso idóneo que no fue agotado, aseverando que el mismo es la Acción de Tutela; se genera, entonces, la siguiente conclusión: no habría razón para aducir como idóneos el Derecho de Petición y la Solicitud escrita de Revisión a los inspectores respectivos en las Fuerzas Militares o la Policía Nacional, puesto que, a la postre, en lugar de haber demostrado la existencia de multiplicidad de recursos adecuados que debió haber agotado la víctima, lo que logró demostrarle a la $\mathrm{CIDH}$ es que únicamente se ha regulado el Hábeas Data para asuntos financieros y comerciales (Ley Estatutaria 1266 de 2008), y no lo ha hecho para otros temas como el alegado en el presente caso, razón por lo cual la acción de tutela (mecanismo existente hasta el momento para accionar el hábeas data), no constituiría el recurso idóneo a fin de resolver la situación planteada.

Entonces, se esclarece lo siguiente:

1. La Ley 1288 de 2009, de Inteligencia y Contrainteligencia, y su Decreto Reglamentario 3600 de 2009, planteados como recursos idóneos por el Estado, entraron en vigencia el 5 de marzo y el 21 de septiembre de 2009 respectivamente, es decir, con posterioridad a la presentación de la petición (14 de marzo de 2008), por lo cual su agotamiento no habría resultado exigible.

2. El 16 de noviembre de 2010 la Corte Constitucional declaró inconstitucional la Ley de Inteligencia por vicios en el trámite. No obstante, la legislación declarada inconstitucional no establecía criterios específicos para el acceso, actualización y depuración de la información de las bases de datos de inteligencia por lo que no constituía un recurso idóneo para resolver la situación planteada.

Vislumbrándose por parte del Estado una argumentación errónea, pues termina reconociendo que dentro de su jurisdicción los ciudadanos no pueden incoar recursos apropiados, quedando confirmada la falta de acceso, actualización y depuración de la información de las bases de datos de inteligencia, enmarcándose dicha situación dentro de la excepción al agotamiento de los recursos internos prevista en el artículo 46 (2)(a), ¿́para qué alegar la existencia de recursos internos idóneos que a la hora de ocurrida la vulneración de los derechos alegados no estaban disponibles?

Así, y con fundamento en lo anterior, la CIDH toma nota que, habiendo transcurrido más de 10 años de interpuesta la primera denuncia penal ante la Unidad de Derechos Humanos de la Fiscalía General de la Nación, aún no se habría establecido responsabilidad penal de ninguna persona. Actualmente, la Fiscalía 239 Seccional de Bogotá adelanta la investigación con base en la información recibida por la víctima relativa a un presunto plan para asesinarla, investigación a la que se habrían acumulado todas las denuncias interpuestas, misma que aún se encuentra en etapa preliminar, por lo mismo, resulta aplicable la excepción prevista en el artículo 46(2)(c) de la Convención Americana respecto del retardo en el desarrollo del proceso penal interno, toda vez que transcurridos más de 16 años, la investigación se encuentra en etapa preliminar, por lo cual el requisito previsto en materia de agotamiento de recursos internos no resulta exigible.

Otra de las inconsistencias de los estados en sus argumentos hace referencia a las contradicciones y/o falencias argumentativas de los mismos, pues en el Caso Jesús Reynaldo Aguirre Ching Vs Perú, en un primer momento el Estado afirma que dentro del proceso penal iniciado, la víctima no se constituyó como parte civil ni impugnó las decisiones que dentro del él se tomaron; no obstante ello, si participó activamente en el proceso militar como parte civil sin impugnar, en ningún momento, la competencia de la justicia castrense, pero la CIDH fue enfática al aseverar queel argumento resulta del todo improcedente, pues si bien la víctima no impugnó dicha competencia, la Fiscalía solicitó se avocara procesamiento de lesiones y emplazaron a autoridades del fuero militar a que se abstuvieran de investigar tales hechos $y$, sin embargo, fue esta institución quien 
continuo conociendo del caso y, así, emitió decisiones que impedirían la persecución de los únicos imputados en fuero ordinario.

De lo anterior, resulta entonces que el recurso señalado como idóneo por el Estado fue incoado por los propios órganos de jurisdicción interna sin obtener resultado favorable, no siendo entonces adecuado, característica principal que deben tener los recursos conforme los presupuestos del Derecho Internacional, quedando los peticionarios inmersos dentro de las excepciones consagradas en el artículo 46.2 a y b.

Así pues, luego de hacer referencia a la contante omisión estatal, es claro que se hace necesaria e indispensable la actuación de órganos internacionales, debido a que la Jurisdicción Nacional resulta inapropiada, inadecuada e inefectiva para garantizar la protección de los Derechos Humanos, teniendo en cuenta que en primera instancia el Estado denunciado conoció la situación y tuvo oportunidad de corregir la misma ${ }^{4}$, mostrándose entonces negligente o indiferente ante la situación denunciada por las víctimas.

\section{Del pleito pendiente interno}

\section{En el Caso Fredy Alberto Álvarez y familia} Vs Colombia el Estado alega que no se dan las condiciones para aplicar la excepción prevista en el artículo 46.2.c., en virtud de lo siguiente:

\section{Si bien la investigación se trasladó por competencia al fuero penal militar, finalmente esta fue devuelta a la justicia penal ordinaria, debido a una colisión positiva de competencia}

Este traslado permite pensar: ¿̇es necesario promover la colisión de competencias, con el fin de desarrollar la investigación correspondiente

4 Ibíd., párr. 21. (...) Este requisito tiene como objeto permitir que las autoridades nacionales conozcan sobre la supuesta violación de un derecho protegido y, de ser apropiado, tengan la oportunidad de solucionarla antes de que sea conocida por una instancia internacional. dentro de la jurisdicción ordinaria teniendo en cuenta la naturaleza de los hechos (Violación a Derechos Humanos)?; además de ello, no resulta clara la insistencia de los Estados al invocar procedimientos ante la jurisdicción castrense, una vez establecido el precedente interamericano en el sentido de considerar dicha cuerda procesal inadecuada a efectos de obtener justicia, tratándose de vulneraciones a los Derechos Humanos, entendiendo que una investigación debe efectuarse de forma independiente e imparcial, conforme lo estipulado por los artículos 1.1, 25 y 8 de la Convención Americana.

El último de estos contempla lo relativo a la competencia, independencia e imparcialidad de los tribunales como elemento fundamental del debido proceso, pues, de lo contrario, habría impunidad de facto que implica la violación al ordenamiento legal y a los principios de la Convención Americana. Los órganos del sistema interamericano han insistido en que, en un Estado democrático de Derecho, la característica esencial de la jurisdicción penal militar debe ser su carácter restrictivo y excepcional, encaminado a la protección de intereses jurídicos especiales, conforme a la función quela ley asigna a las fuerzas militares, es decir, la justicia militar debe ser utilizada sólo para juzgar militares activos por la presunta comisión de delitos de función en sentido estricto, por lo que las violaciones a los derechos humanos deben ser investigadas, juzgadas y sancionadas por los tribunales penales ordinarios, de acuerdo a la ley (28 de febrero de 2006, párr. 80 - 84).

La investigación del caso por parte de la justicia militar precluye la posibilidad de una investigación objetiva e independiente ejecutada por autoridades judiciales no ligadas a la jerarquía de mando de las fuerzas de seguridad. El hecho de que la investigación de un caso haya sido iniciada en la justicia militar puede imposibilitar una condena aún si el caso pasa luego a la justicia ordinaria, dado que probablemente no se han recopilado las evidencias necesarias de manera oportuna y efectiva. 
Asimismo, la investigación de los casos que permanecen en el fuero militar, puede ser conducida de manera de impedir que éstos lleguen a la etapa de decisión final (CIDH, 20 de febrero de 2003, párr. 28; 17 de marzo de 2010, párr. 32).

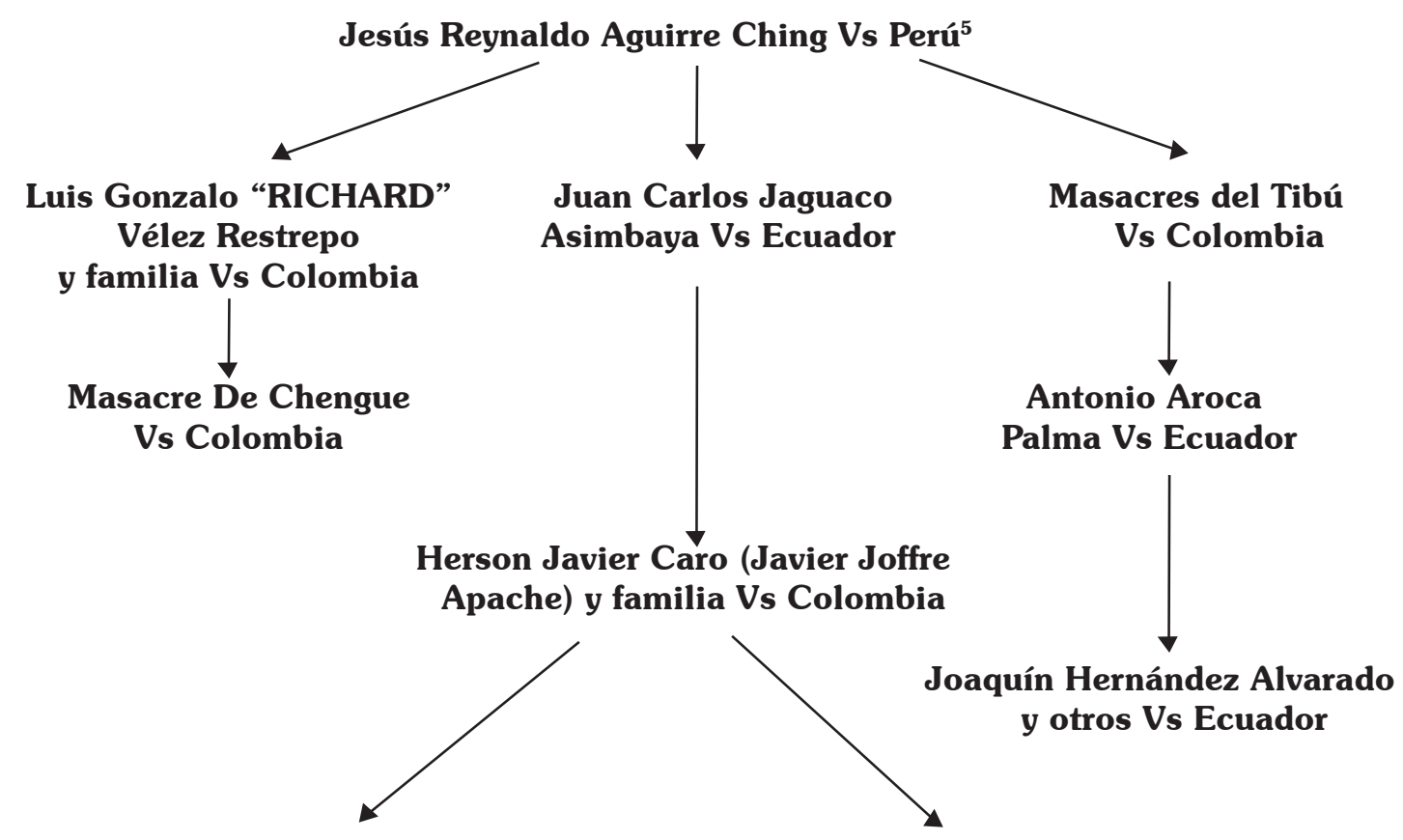

\section{Leonel De Jesús Isaza Echeverry Y otro Vs Colombia}

\section{Carlos Manuel Prada González y otro Vs Colombia}

Fuente: Elaboración propia con base en la CIDH (22 de marzo de 2011, párr. 26;24 de julio de 2008, párr. 74; 21 de junio de 2010, párr. 36; 18 de marzo de 2010, párr. 119; 23 de julio de 2007, párr. 49; 5 de agosto de 2009, párr. 26; 16 de julio de 2009, párr. 33;27 de febrero de 2002, párr. 18; 6 de abril de 2001, párr. 22; 25 de septiembre de 1998, párr. 44).

\section{La Investigación desarrollada en la Procuraduría fue archivada porque no obra experticio técnico}

El Estado no tuvo en cuenta que los procesos disciplinarios (22 de julio de 2011, párr. 40) ${ }^{6}$ han sido descalificados en la jurisprudencia interamericana cuando se utilizan como medio

5 Se presenta el nicho citacional del escenario convencional "Justicia Penal Militar".

6 (...) la Comisión ha sostenido anteriormente que las decisiones emitidas en las jurisdicciones disciplinaria y contencioso administrativa no constituyen recursos idóneos para satisfacer el artículo 46 de la Convención Americana. para investigar y sancionar a los responsables de violaciones a Derechos Humanos, como la Vida y la Libertad. Además, si no obraba dentro del expediente el medio de prueba en cuestión, debió haberse solicitado la práctica del mismo, lo que demuestra que existieron falencias en el desarrollo de la investigación.

\section{Existencia de proceso de reparación directa}

Aunque el intento del Estado en este caso es demostrar que existió por parte de sus autoridades judiciales el reconocimiento de vulneración de los Derechos Humanos y reconocimiento de su responsabilidad por los mismos hechos, esto no 
justifica ni remplaza la no individualización y sanción de los responsables materiales, es decir, la demora en el desarrollo y culminación del proceso penal que es el idóneo para proteger los derechos en casos como el presente.

Respecto a los procesos tramitados ante la jurisdicción disciplinaria y la jurisdicción contencioso administrativa, el precedente de la Comisión ha sostenido que dichas cuerdas procesales (CIDH, 15 de octubre de 2007, párr. 34) no constituyen recursos idóneos a efectos de analizar la admisibilidad de un reclamo de la naturaleza penal, pues la jurisdicción disciplinaria no constituye una vía suficiente para juzgar, sancionar y reparar las consecuencias de violaciones a los derechos humanos (CIDH, 23 de octubre de 2010, párr. 36 y 12 de julio de 2010, párr. 48).

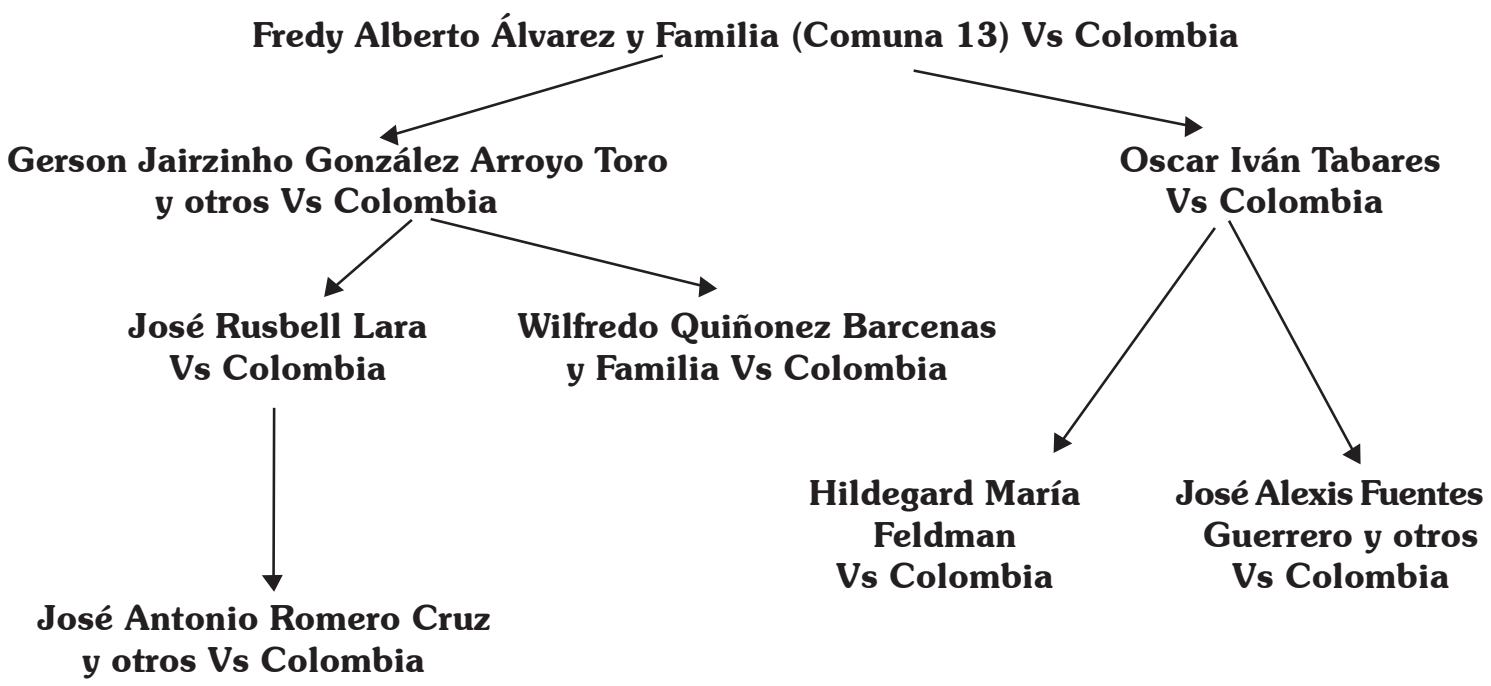

Fuente: Elaboración propia con base en la CIDH (22 de julio de 2011, párr. 40; 23 de octubre de 2010, párr. 45; 13 de octubre de 2005, párr. 26, 5 de agosto de 2009, párr. 34, 5 de agosto de 2009, párr. 42;15 de octubre de 2007, párr. 34; 17 febrero 1996, párr. 71 y 13 de abril de 1999, párr. 51).

\section{Las excepciones al agotamiento de recursos no aplican, en razón a que los tribunales internos revisaron la validez de los recursos}

El Estado no es claro en cuanto a las revisiones hechas por sus autoridades, lo que deja un vacío que podría interpretarse como si quienes hubiesen revisado tal validez fuesen las jurisdicciones disciplinarias y contenciosa - administrativa; no logrando allegar prueba de la incompetencia del Sistema Interamericano. En este sentido, los agentes estatales no lograron convencer a la $\mathrm{CIDH}$ de la subsidiaridad de su jurisdicción por omitir especificaciones respecto a los recursos que

7 Se presenta el Nicho Citacional del Escenario Convencional "Jurisdicción Contenciosa y Disciplinaria". aduce fueron revisados. Entonces, si el Estado desarrolla con mayor precisión este argumento, la decisión de la CIDH hubiese declarado: el mero hecho de que un recurso no produzca resultado favorable a las pretensiones de quien lo ha interpuesto no demuestra, por sí solo, la inexistencia o agotamiento de todos los recursos (6 de octubre de 1993, párr. 28).

\section{No existe una práctica o política ordenada o tolerada por el Estado para impedir la utilización de los recursos internos}

Cumple en este caso el Estado con la obligación que se consagra en el artículo 31 del Reglamento de la $\mathrm{CIDH}$, pero no entrega ningún argumento que tienda, al menos, a persuadir a la $\mathrm{CIDH}$ acerca de la veracidad de este alegato. 
En el caso bajo análisis, en el intento por probar que el retardo que se produjo no fue por motivos injustificados sino, por el contrario, que se dio en virtud de criterios de razonabilidad del plazo, debido a: 1) Alta tasa de homicidios en la Comuna 13 (Complejidad de la situación), y 2) Alto porcentaje de acciones terroristas, secuestros, extorsión, despojo de propiedades y desplazamiento forzado en la zona. De acuerdo a lo precedente, se puede establecer que el Estado se contradice al aseverar que si bien existe una alta tasa de homicidios, esta ha venido en descenso en un $70 \%$, y no logra determinar la relación que existe entre los acontecimientos terroristas y demás situaciones de orden público con las acciones judiciales que los agentes estatales debieron iniciar de oficio.

Así, la CIDH concluye que:

1. No se ha llevado a cabo una investigación adecuada, mediante la cual se haya identificado, juzgado y sancionado a los responsables, por lo que la investigación ha resultado ineficaz.

2. Existe un retardo injustificado, por lo que se configura la excepción a la regla de agotamiento de los recursos internos, pues transcurridos más de nueve años no hay indicios de movimiento procesal reciente, el proceso penal se encuentra aún en etapa preliminar quedando, entonces, los peticionarios exceptuados de agotar los recursos internos antes de recurrir al sistema interamericano en búsqueda de protección.

Bajo la misma línea argumentativa, encontramos el Caso Jimmy Rafael Guerrero Vs Venezuela en el cual la CIDH estableció que, de acuerdo a los hechos acaecidos, no resultan aplicables las excepciones establecidas en los artículos 46(2) (a) y 46(2)(b) de la Convención, en vista de que en el Estado existe el proceso legal para protección de los derechos que, se alega, han sido violados (Vida e Integridad), no siendo el Estado responsable del no acceso a los recursos de jurisdicción interna, pues los agentes estatales no han impedido el accionar de los mismos.
El Estado, en esta ocasión, se limita a decir que se requirió la remisión de todas las actuaciones a fin de emitir el acto conclusivo correspondiente, manifestando con la siguiente premisa: las autoridades competentes están activamente impulsando las diligencias y han garantizado todos los derechos que los peticionarios alegan como violados, y solicita a la Comisión que declare el reclamo inadmisible no demostrando esta afirmación. Teniendo en cuenta que, transcurridos más de siete años de iniciada la investigación, ésta aún se encontraría en etapa preliminar, sin que se haya adelantado un gran número de las diligencias ordenadas por el Ministerio Público al CICPC y sin la determinación de la responsabilidad penal de ninguno de los presuntos autores de los hechos alegados, llegando a ser aplicable la excepción prevista en el artículo 46(2) (c) de la Convención Americana, respecto del retardo en el desarrollo de los procesos judiciales internos.

\section{De las excepciones del artículo 46.2 - artículo 31.3}

Cabe mencionar ahora la fácil apreciación de la Inversión de la Carga Probatoria que desarrolla el artículo 31.3 del Reglamento de la CIDH, en razón a que advierte lo siguiente: "Cuando el peticionario alegue la imposibilidad de comprobar el cumplimiento del requisito señalado en este artículo, corresponderá al Estado en cuestión demostrar que los recursos internos no han sido agotados, a menos que ello se deduzca claramente del expediente" (CIDH, 15 de octubre de 2007, párr. 43); es decir, si bien es obligación del Estado probar la excepción cuando se invocan las excepciones al Agotamiento de los Recursos, tratándose de los eventos del artículo 46.2 a y c, en razón a las responsabilidades asumidas internacionalmente por los estados partes, como son: garantía del debido proceso y el trámite de procesos ágiles y expeditos dentro de un tiempo preestablecido; no obstante ello, en los eventos que consagra el numeral b del mismo artículo (no se haya permitido al presunto lesionado en sus derechos el acceso a los recursos de la jurisdicción interna o haya sido impedido de agotarlos), en especial, el evento de los impedimentos soportados por los peticionarios, resulta injusto para el Estado la obligación probatoria 
respecto a un criterio que proviene de circunstancias y eventos que únicamente conoce la víctima o el peticionario, desconociendo esta situación el principio procesal de Igualdad de Armas.

Teniendo en cuenta, entonces, lo enunciado en principio por el articulo 31(3) que expresa la imposibilidad de agotamiento por parte de los peticionarios, aspecto este que hace parte de lo decidido por la CIDH en el Informe que sobre el Fondo se adopte, pues según lo ha establecido la $\mathrm{CIDH}$ "La invocación de las excepciones a la regla de agotamiento de los recursos internos previstas en el artículo 46(2) de la Convención se encuentra estrechamente ligada a la determinación de posibles violaciones a ciertos derechos en ella consagrados, tales como las garantías de acceso a la justicia"(CIDH, 12 de julio de 2010, párr. 45; 5 de agosto de 2009, párr. 29 y 5 de marzo de 2008, párr. 29 y 22 de octubre de 2003, párr. 28).

Ello no resulta concordante con la afirmación que el mismo órgano hace: "el artículo 46(2), por su naturaleza y objeto, es una norma con contenido autónomo vis á vis las normas sustantivas de la Convención. Por lo tanto, la determinación de si las excepciones a la regla de agotamiento de los recursos internos resultan aplicables al caso en cuestión debe llevarse a cabo de manera previa y separada del análisis del fondo del asunto, ya que depende de un estándar de apreciación distinto de aquél utilizado para determinar la posible violación de los artículos 8 y 25 de la Convención" (CIDH, 22 de julio de 2011, párr. 33; 24 de marzo de 2010, párr. 48 y 5 de agosto de 2009, párr. 38).

El Estado se encuentra probando unas situaciones fundamentadas en razones que serán discutidas en otra etapa procesal, ya que según la CIDH "las causas y los efectos que impidieron el agotamiento de los recursos internos serán analizados en el informe que adopte la Comisión sobre el fondo de la controversia"(CIDH, 30 de octubre de 2008, párr. 40; 21 de octubre de 2006, párr. 26; 26 de febrero de 2004, párr. 32 y 22 de octubre 2003, párr. 58).

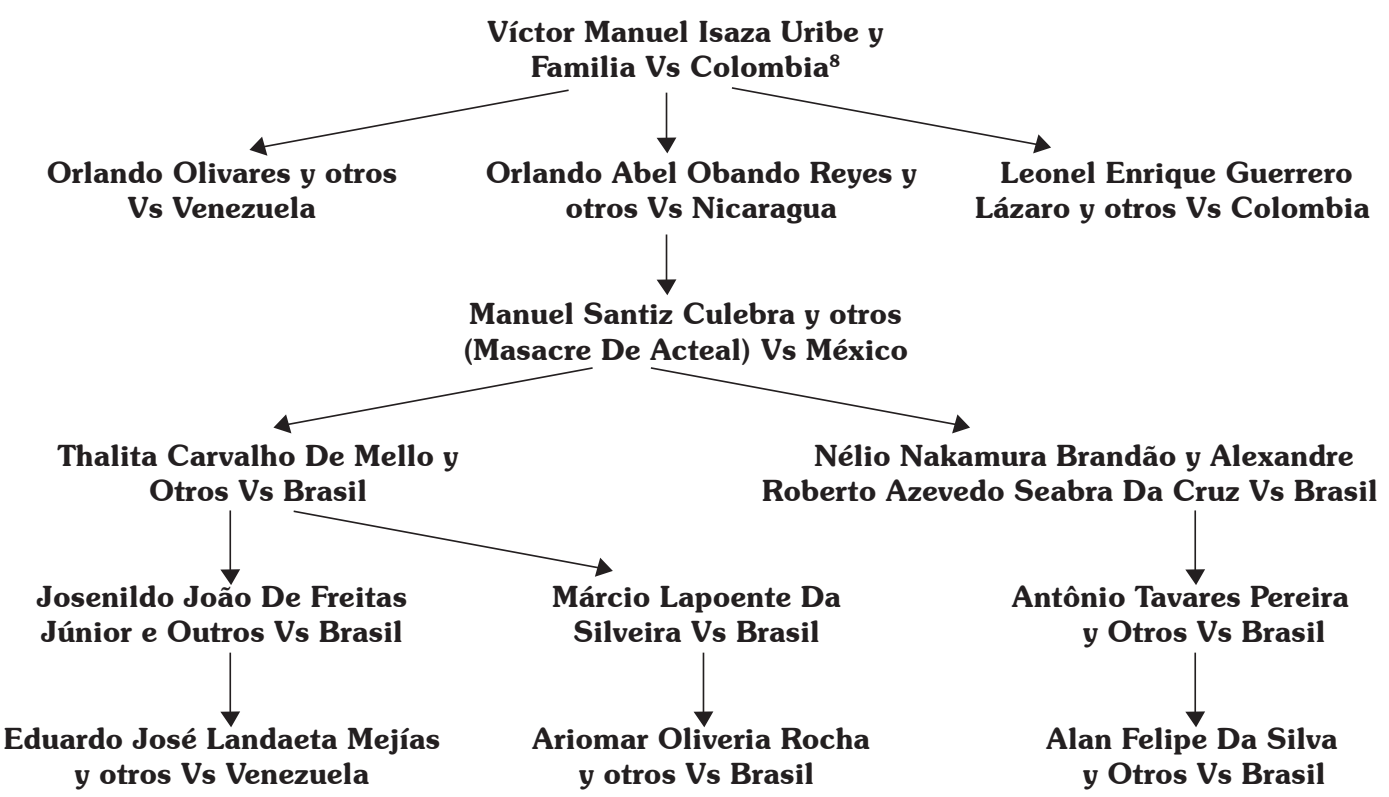

Fuente: Elaboración propia con base en la CIDH (22 de julio de 2011, párr. 52; 23 de marzo de 2011, párr. 35; 22 de marzo de 2011, párr. 39 (b); 22 de marzo de 2011, párr. 33 (c); $1^{\circ}$ de noviembre de 2010, párr. 43; 23 de octubre de 2010, párr. 22; 17 de marzo de 2010, párr. 25; 22 de julio de 2009, párr. 31; 16 de octubre de 2008, párr. 75; 29 de octubre de 2009, párr. 36; 9 de marzo de 2007, párr. 47; 3 de marzo de 2007, párr. 27 y 23 de julio de 2007, párr. 55)

8 Se presenta el Nicho Citacional del Escenario Convencional "Inversión de la Carga Probatoria y Prejuzgamiento". 
Retardo injustificado Vs Complejidad del asunto

Continuando con el tema antes propuesto, cabe recordar que el artículo 46.2.c., exime a las víctimas y/o peticionarios de agotar los recursos internos cuando exista un retardo injustificado, mismo que tuvo ocurrencia en el Caso Orlando Olivares y otros Vs Venezuela, en el cual el proceso penal se encuentra aún en trámite después de cinco años de su iniciación, en donde el Estado ha olvidado que es su deber explicar porqué aún se encuentra el proceso pendiente de decisión definitiva, es decir, no propendió por demostrar que los hechos investigados sean de una determinada complejidad; aduciendo, además, que no habrían interpuesto acción de amparo constitucional, sin expresar cuál es el motivo de invocación de la misma, es decir, porqué resultaba procedente. De lo que finalmente se puede concluir, esque, tratándose de vulneraciones al Derecho a la Vida, el escenario ideal para la protección del mismo es la interposición, desarrollo y culminación de un proceso penal que debe iniciarse de oficio por la autoridades judiciales, lo que implica que son ellas las que en realidad tienen que darle tramite al proceso y garantizar el debido proceso.

Bajo la misma línea que se viene tratando, encontramos el Caso Orlando Abel Obando Reyes y otros (Personas Detenidas En La Zona Rural Del Municipio De Nueva Guinea) Vs Nicaragua, en el cual el Estado nuevamente alega el no agotamiento de recursos por parte de los peticionarios, aduciendo que el proceso penal todavía estaba en curso y, por tanto, el conocimiento de los hechos por parte de los órganos interamericanos resulta absurdo.

Frente a estos planteamientos, la $\mathrm{CIDH}$ es clara al manifestar que al no existir esclarecimiento de los hechos ni garantías de acceso a la justicia es evidente la contradicción entre los hechos y la normatividad de la CADH (44, 46.1.a. y 46.2). Estas afirmaciones se fundamentan en el desarrollo del proceso penal, en el cual la acusación tuvo lugar un año y medio después de acaecidos los hechos, sumándole a ello que dos policías aun se encuentran prófugos de la justicia, sin muestra alguna por parte del Estado de actuaciones tendientes a conseguir la presentación de los mismos ante la autoridad judicial correspondiente.

Y es que la CID reconoce que, si bien existieron investigaciones por ejecuciones extrajudiciales $y$ violaciones sexuales, estas no trascendieron, pues la idea de una sola persona condenada no representa la realización de justicia, dado que, y según palabras de la $\mathrm{CIDH}$, la naturaleza y multiplicidad de hechos conllevarían a establecer más y mejores resultados.

\section{En el Caso Arles Edisson Guzmán Medina} Vs Colombia, en respuesta a los alegatos de los peticionarios que afirmaban que el recurso de Habeas Corpus se encuentra destinado a proteger personas privadas de la libertad arbitrariamente por el Estado y no para retenciones y desapariciones que realizan particulares con connivencia u omisión del Estado; los agentes estatales reconocen que el mismo si resulta idóneo y que, además, existen otros mecanismos como es el de la Búsqueda Urgente de Personas Desaparecidas; no compartiendo entonces con los peticionarios la afirmación de que el Proceso Penal era el único recurso disponible, mismo que a la postre resultó en un retardo injustificado, en opinión de los peticionarios. No obstante ello y contrario al caso precedente, el Estado advierte que si bien se presentó un retardo en el desarrollo del proceso penal, este se encuentra justificado, en las siguientes razones:

1. La denuncia se formalizó un año después de ocurridos los hechos, lo que impidió una acción inmediata y la no obtención de resultados prontos.

2. Complejidad del asunto, en razón al orden público para la época de los hechos.

Frente a los argumentos descritos, caberesaltar lo siguiente, aunque sea de conocimiento general: "Los precedentes establecidos por la Comisión señalan que toda vez que se cometa un delito perseguible de oficio, el Estado tiene la obligación de promover e impulsar el proceso penal y que, en esos casos, éste constituye la vía idónea para 
esclarecer los hechos, juzgar a los responsables y establecer las sanciones penales correspondientes, además de posibilitar otros modos de reparación de tipo pecuniario" (CIDH, 22 de julio de 2011, párr. 38; 22 de marzo de 2011, párr. 28; 19 de febrero de 2011, párr. 27 y 4 de enero de 2011, párr. 28 y 30) no procediendo entonces el argumento de la inactividad de los peticionarios por lo menos en la interposición de la acción correspondiente.
Ahora, respecto del segundo argumento, considero que el Estado se queda corto en este, toda vez que no hace referencia específica a la situación de orden público, es decir, cuáles eran las causas que perturbaron el mismo;esta omisión no hace fácil la tarea de determinar si en realidad este fue un factor determinante para la demora de la decisión final y definitiva dentro del proceso penal.

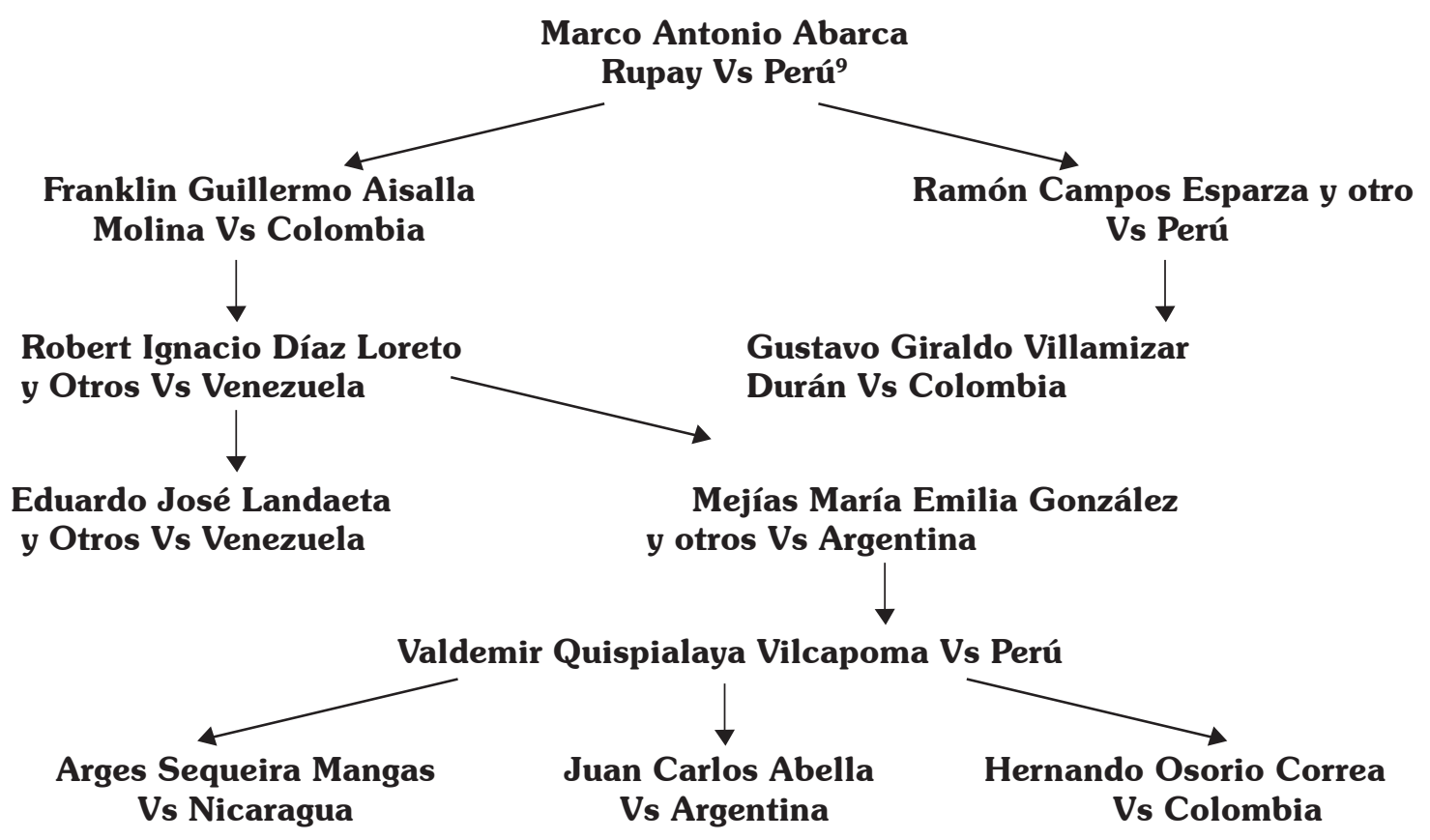

Fuente: Elaboración propia con base en la CIDH (22 de julio de 2011, párr. 38; 21 de octubre de 2010, párr. 134; 24 de julio de 2008, párr. 47; 9 de marzo de 2007, párr. 43; 2 de marzo de 2006, párr. 34; 25 de febrero de 2005, párr. 35; 18 de febrero de 1998, párr. 96 y 97; 18 de noviembre de 1997, párr. 392; 3 de octubre de 2000, párr. 24; 29 de octubre de 2009, párr. 33)

En cuanto al segundo criterio establecido para la interposición de la excepción de falta de agotamiento de Recursos Internos, (la carga probatoria es del Estado que la invoca), "toda vez que un Estado alega la falta de agotamiento de los recursos internos por parte del peticionario, tiene la carga de demostrar que los recursos que no han sido agotados resultan "adecuados" para subsanar la violación alegada, vale decir que

9 Se presenta el Nicho Citacional del Escenario Convencional "Retardo Injustificado Vs. Complejidad del Asunto”. la función de esos recursos dentro del sistema del derecho interno es idónea para proteger la situación jurídica infringida" (CIDH, 19 de febrero de 2011, párr. 25; $1^{\circ}$ de noviembre de 2010, párr. 28).

\section{CONCLUSIONES}

La excepción preliminar falta de agotamiento de recursos internos resulta improcedente, en razón a dos motivos que a continuación se describen. En primer lugar, los agentes estatales 
omiten el estudio de las decisiones de la CIDH y su precedente en desarrollo de su Defensa; se puede inferir que la desestimación de la excepción preliminar falta de agotamiento de recursos internos se debe al escaso o nulo análisis del precedente establecido por la $\mathrm{CIDH}$ de parte de los agentes estatales, lo que conlleva a la presentación y exposición de argumentos insuficientes y mediocres. Es decir, si la defensa del Estado fuese responsable en la consecución de argumentos completos, la excepción preliminar procedería de forma continua, pues en el mencionado precedente se advierten las exigencias y criterios a seguir por parte de los estados y sus agentes.

Y segundo, la inadecuada presentación y argumentación de la misma. Aseveración realizada, luego del análisis descriptivo de los informes de admisibilidad $e$ inadmisibilidad expedidos por la $\mathrm{CIDH}$, pues los estados, en el planteamiento de sus defensas, comenten errores y plasman inconsistencias que convencen a la $\mathrm{CIDH}$ de lo siguiente: los peticionarios están desprotegidos a nivel interno; esta situación lleva a que el Sistema Interamericano se convierta en un medio de utilización apremiante ante la inminente vulneración de los Derechos Humanos.

Es decir, para que la excepción preliminar falta de agotamiento de recursos nternosresulte ser un mecanismo de Defensa Estatal efectivo, debe haber un mayor compromiso de los agentes estatales a la hora de presentar argumentos que pretendan probar la idoneidad de los recursos que ellos alegan son los adecuados para subsanar las violaciones a los Derechos Humanos.

Pues dentro del precedente emitido por la Comisión, existen 23 casos en que la interposición de la excepción falta de agotamiento de recursos internos ha resultado procedente $\mathrm{y}$, por tanto, favorable para los Estados que la interponen. A continuación, se describirán tres de ellos:

En el CasoTeófilo Sánchez Minaya Vs Perú, el Estado asevera que la presunta víctima agotó indebidamente los recursos de la jurisdicción interna, incumpliendo, por lo tanto, el requisito previsto en el artículo 46.1.a) de la Convención; concediéndole la $\mathrm{CIDH}$ la razón en este caso, en virtud de la acción de amparo interpuesta el 21 de agosto de 2001 que fue desestimada, debido al incumplimiento de exigencias procesales previstas en la legislación peruana, y ante la ausencia de alegatos concretos sobre la eventual incompatibilidad de dicha legislación con la Convención Americana.

La CIDH concluye que la presunta víctima no agotó debidamente los recursos formulados ante los órganos de la jurisdicción interna(CIDH. 22 de julio de 2011, párr. 28). Entonces, en el caso antes mencionado, se tiene que por medio de la acción de amparo lo que se pretendía era obtener la inaplicabilidad de la Resolución Directoral que despojaba a la presunta víctima de su cargo; dicho recurso fue desestimando el 7 de junio de 2004 por el Tribunal Constitucional, debido al incumplimiento del plazo establecido en la legislación interna con relación al recurso administrativo de apelación.

Así, se concluye que dado el afán de la presunta víctima por obtener respuesta favorable por parte de los autoridades judiciales, intentó hacer del sistema Interamericano una Cuarta Instancia lo que, a viva voz, no procede, pues conforme el precedente de la $\mathrm{CIDH}$, no puede hacer las veces de un tribunal de alzada para examinar supuestos errores de derecho o de hecho que puedan haber cometido los tribunales nacionales dentro de los límites de su competencia(CIDH. 13 de octubre de 2004, párr. 41; 20 de febrero de 2003, párr. 38; 10 de octubre de 2001, párr. 10 y 15 de octubre de 1996, párr. 71).

Continuando con el argumento anterior, en el Caso Leonel Enrique Lázaro y otros Vs Colombia, la CIDH asevera que, dadas las características del presente caso y el lapso transcurrido desde los hechos materia de la petición (17 años), resulta aplicable la excepción prevista en el artículo 46(2) (c) de la Convención Americana respecto del retardo en el desarrollo de los procesos judiciales internos. 
Sin embargo, dicho órgano tuvo en cuenta lo aducido por el Estado, en cuanto al trámite surtido en la jurisdicción contencioso - administrativa, el peticionario pretende utilizar el Sistema Interamericano como una cuarta instancia, pues la única presunta violación al debido proceso alegada en el reclamo es la negativa del Consejo de Estado de estudiar el recurso extraordinario de súplica; dicha decisión se sustentó en el artículo 194 del Código Contencioso Administrativo, y, teniendo en cuanta que en vista de la inconformidad del peticionario frente a dicha negativa éste interpuso una acción de tutela que fue admitida a estudio; sin embargo, las pretensiones no prosperaron. Tan es así que, en relación con la improcedencia del recurso de Súplica por agotamiento indebido de parte del peticionario, y teniendo en cuenta que tratándose de recursos extraordinarios no es obligación de los peticionarios y/o víctimas el agotamiento de estos, resulta sorprendente la procedencia de la excepción sub examen, pues

"[1]a jurisprudencia del sistema [interamericano] ha establecido que si bien en algunos casos dichos recursos extraordinarios pueden ser adecuados para enfrentar violaciones a los derechos humanos, como norma general los únicos recursos que es necesario agotar son aquellos cuyas funciones, dentro delsistema jurídico, son apropiadas para brindar protección tendiente a remediar una infracción de determinado derecho legal. En principio se trata de recursos ordinarios, y no extraordinarios" (CIDH. 24 de octubre de 2003, párr. 45).

De ello surge un cuestionamiento, conforme lo aducido: ¿si no se tiene la obligación de agotar la vía contencioso - administrativa, porqué tuvo que agotarse el Recurso Extraordinario de Súplica contra la decisión de esta jurisdicción?; así las cosas, en este caso la CIDH hace de la jurisdicción contenciosa una vía idónea o apropiada para el reclamo y reparación de posibles vulneraciones a los Derechos Humanos convirtiendo, a su vez, el recurso de Súplica en un procedimiento válido y agotable dentro de la jurisdicción nacional, ya que admite que es necesaria la elaboración de un nuevo poder para interponer dicho recurso, exigencia realizada por la Sala Plena de lo Contencioso Administrativo del Consejo de Estado, en razón a que los magistrados establecen que por tratarse de un recurso extraordinario y por ser procedente únicamente contra sentencias ejecutoriadas, a menos que quien actúe en su propio nombre ostente y demuestre la calidad de abogado inscrito.

En este caso se observa que, tras la interposición del mencionado recurso y hecha la anterior exigencia, el peticionario le solicitó al Consejo de Estado tener en cuenta los poderes anexados para la presentación de la demanda de reparación directa que obran en el expediente, obteniendo este respuesta desfavorable, ya que dichos poderes no le conferían la facultad expresa para interponer recurso extraordinario de súplica, no explicando el peticionario el por qué no pudo cumplir con lo requerido por el Tribunal ni ha alegado por qué no era razonable el requerimiento. La CIDH decidió que el peticionario no agotó debidamente los recursos internos.

Nuevamente, en el Caso Miembros del Sindicato de obreros de Unión Productores de leche S.A. Vs. Perú, la $\mathrm{CIDH}$ se pronunció respecto al incumplimiento de las decisiones judiciales o autoridades administrativas estatales, aduciendo que, en procura de analizar el cumplimiento del requisito de agotamiento de los recursos internos, las presuntas víctimas deben poner en conocimiento de la autoridad respectiva lasituación para que esta tenga la oportunidad de actuar conforme a la legislación, adoptando las medidas necesarias para que la decisión sea ejecutada (CIDH, 16 de marzo de 2010, párr. 35 y 27 de marzo de 2009, párr. 38).

Los hechos del caso en mención se circunscriben en el incumplimiento de las sentencias dictadas entre 1988 y 1991 en los procesos laborales que ordenaron la liquidación de beneficios sociales por parte de la empresa Unión Productores de Leche S.A. a 235 trabajadores, cuyo despido fue declarado arbitrario. 22, lo cual desconoce el Estado peruano al aseverar que el incumplimiento de las sentencias laborales no es atribuible a las autoridades judiciales 
peruanas, sino la situación de insolvencia de la empresa demandada, no siendo utilizados por las presuntas víctimas los recursos a su disposición,como los embargos y el remate de bienes; recursos que resultan idóneos y eficaces, aunque no suficientes para abonar las deudas. Elementos que son considerados por la $\mathrm{CIDH}$ y decide que las presuntas víctimas debieron invocar los mecanismos previstos en la legislación interna, en el marco del proceso de ejecución, pues no corresponde al órgano interamericano reemplazar las autoridades de la jurisdicción peruana en la determinación de los efectos de tal situación que debe ser resuelta en los procedimientos de la jurisdicción interna.

\section{REFERENCIAS}

CIDH. Informe No. 69/10. Petición 11.444. Admisibilidad. Amparo Constante Merizalde Vs. Ecuador. 12 de julio de 2010.

CIDH. Informe $\mathrm{N}^{\circ}$ 75/07. Petición 12.322. Admisibilidad. Antonio González Méndez Vs. México. 15 de octubre de 2007.

CIDH. Informe N01/09. Petición 1491-05. Admisibilidad. Benito Antonio Barrios y otros Vs. Venezuela. 17 de enero de 2009.

CIDH. Informe No 87/06. Petición 668-05. Admisibilidad. Carlos Alberto Valbuena y Luis Alfonso Hamburger Diaz Granados Vs. Colombia. 21 de octubre de 2006.

CIDH. Informe No. 18/09.Petición 525-04. Admisibilidad. Carlos Fernández Gadea Vs. Paraguay. 19 de marzo de 2009.

CIDH. Informe No. 84/98. Caso 11.710. Carlos Manuel Prada González y Evelio Antonio Bolaño Castro Vs. Colombia. 25 de septiembre de 1998.

CIDH. Informe No 51/03. Petición 11.819., Admisibilidad. Christian Daniel Domínguez Domenichetti Vs Argentina. 24 de octubre de 2003.
CIDH. Informe $\mathrm{N}^{\mathrm{O}}$ 13/08. Petición 844-05. Admisibilidad. Comunidad De Río Negro del Pueblo Indígena Maya y sus Miembros Vs. Guatemala. 5 de marzo de 2008.

CIDH. Informe N75/09. Petición 286-08. Admisibilidad. Comunidades Indígenas Ngöbe y sus Miembros en el Valle del Río Changuinola Vs. Panamá. 5 de agosto de 2009.

CIDH. Informe $\mathrm{N}^{\circ}$ 63/10. Petición 1119-03. Admisibilidad. Comunidad Garífuna Punta Piedra y sus Miembros Vs. Honduras. 24 de marzo de 2010.

CIDH. Informe $\mathrm{N}^{\circ}$ 16/03. Petición 346-01. Inadmisibilidad. Edison Rodrigo Toledo Echeverría Vs Ecuador. 20 de febrero de 2003.

CIDH. Informe No. 4/03. Petición 11.820. Admisibilidad. Eldorado dos Carajás Vs. Brasil. 20 de febrero de 2003.

CIDH. Informe $\mathrm{N}^{\circ} 140 / 10$. Petición 4357-02. Admisibilidad. Familia De José Leonardo Abril Armijos Vs. Ecuador. $1^{\circ}$ de noviembre de 2010.

CIDH. Informe No. 13/10. Petición 480-00. Fidel Gutiérrez Gayoso Vs. Perú. 16 de marzo de 2010.

CIDH. Informe No. 64/09. Caso 12.182. Admisibilidad. Florentino Rojas Vs. Argentina. 4 de agosto de 2009.

CIDH. Informe No. 103//11. Petición 1142-04. Admisibilidad. Fredy Alberto Álvarez y familia (COMUNA 13) Vs. Colombia Gabriel Egisto Santillan Vs. Argentina. 22 de octubre 2003.

CIDH. Informe No. 69/08. Petición 681-00. Admisibilidad. Guillermo Patricio Lynn Vs. Argentina. 16 de octubre de 2008.

CIDH. Informe No. 123/10. Caso 11.144. Admisibilidad. Gerson Jairzinho González Arroyo y otros Vs. Colombia. 23 de octubre de 2010.

CIDH. Informe No. 72/09. Petición 11.538. Admisibilidad. Herson Javier Caro (JAVIER 
APACHE) y familia Vs. Colombia. 5 de agosto de 2009.

CIDH. Informe No. 72/09. Petición 11.538. Admisibilidad. Herson Javier Caro (JAVIER APACHE) y familia Vs. Colombia. 5 de agosto de 2009.

CIDH. Informe No. 1/10. Petición 2723-02. Admisibilidad. Homero Flor Freire Vs. Ecuador. 15 de marzo de 2010.

CIDH. Informe No. 40/08. Petición 270-07. Admisibilidad. I.V. Vs. Bolivia. 23 de julio de 2008.

CIDH. Informe $\mathrm{N}^{\circ}$ 87/08. Petición 558-05. Admisibilidad. Jeremy Smith Vs. Jamaica. 30 de octubre de 2008.

CIDH. Informe No. 11/11. Petición 697-04. Admisibilidad. Jesús Reynaldo Aguirre Ching Vs. Perú. 22 de marzo de 2011.

CIDH. Informe No. 4/11. Petición 289-08. Admisibilidad. Jimmy Rafael Guerrero Vs Venezuela. 19 de febrero de 2011.

CIDH. Informe No. 11/02. Petición 12.394. Admisibilidad. Joaquín Hernández Alvarado y otros Vs. Ecuador. 27 de febrero de 2002.

CIDH. Informe No. 59/09. Petición 489-02. Admisibilidad. Joffre Antonio Aroca Palma Vs. Ecuador. 16 de julio de 2009.

CIDH. Informe No. 43/09. Petición 1166-05. Jorge Rafael Valdivia Ruiz Vs. Perú. 27 de marzo de 2009.

CIDH. Informe No. 61/99. Caso 11.519. José Alexis Fuentes Guerrero y otros Vs. Colombia. 13 de abril de 1999.

CIDH. Informe No. 74/07. Petición 1136-03. Admisibilidad. José Antonio Romero Cruz, Rolando Ordoñez Álvarez y Norberto Hernández Vs. Colombia. 15 de octubre de 2007.

CIDH. Informe No. 70/09. Petición 151405. Admisibilidad. José Rusbell Lara Vs. Colombia. 5 de agosto de 2009.
CIDH. Informe No. 64/10. Petición 245-05. Admisibilidad. Juan Carlos Jaguaco Asimbaya Vs. Ecuador. 21 de junio de 2010.

CIDH. Informe No. 7/11. Petición 843-04. Admisibilidad. Leonel Enrique Lázaro Ospina y otros Vs. Colombia. 22 de marzo de 2011(c).

CIDH. Informe No. 47/08. Petición 864-05. Admisibilidad. Luis Gonzalo "RICHARD” Vélez Restrepo y familia Vs. Colombia. 24 de julio de 2008.

CIDH.Informe No 45/04. Petición 369-01. Inadmisibilidad. Luis Guillermo Bedoya de Vivanco Vs Perú. 13 de octubre de 2004.

CIDH. Informe $\mathrm{N}^{\circ}$ 83/06. Petición 641-03. Admisibilidad. Manoel Luiz Da Silva Vs. Brasil. 21 de octubre de 2006.

CIDH. Informe No. 109/11. Petición 1194-04. Admisibilidad. Marco Antonio Abarca Rupray Vs Perú. 22 de julio de 2011.

CIDH. Informe No. 136/09. Petición321-05. Admisibilidad. María Inés Chinchilla Sandoval Vs. Guatemala. 13 de noviembre de 2009.

CIDH. Informe No. 92/06. Petición 95-04. Admisibilidad. María Isabel Véliz Franco Vs. Guatemala. 21 de octubre de 2006.

CIDH. Informe $\mathrm{N}^{\circ}$ 47/10. Petición 1325-05. Admisibilidad. Masacre Estadero "EL ARACATAZZO" Vs. Colombia. 5 de marzo de 2008.

CIDH. Informe No. 51/10. Petición 1166-05. Admisibilidad. Masacres Del Tibú Vs. Colombia. 18 de marzo de 2010.

CIDH. Informe No. 45/07. Petición 1268-05. Admisibilidad. Masacre de Chengue Vs. Colombia. 23 de julio de 2007.

CIDH. Informe No. 2/06. Caso 12.130. Fondo. Miguel Orlando Muñoz Guzmán Vs. México. 28 de febrero de 2006. 
CIDH. Informe $\mathrm{N}^{\circ}$ 83/03. Petición 12.358. Admisibilidad. Octavio Rubén González Acosta Vs. Paraguay. 22 de octubre de 2003.

CIDH. Informe No. 14/11. Petición 1347-07. Admisibilidad. Orlando Olivares y otros (MUERTES EN LA CÁRCEL DE VISTA HERMOSA) Vs. Venezuela. 23 de marzo de 2011.

CIDH. Informe No. 9/11. Petición 1205-07. Admisibilidad. Orlando Abel Obando Reyes y otros (PERSONAS DETENIDAS EN LA ZONA RURAL DEL MUNICIPIO DE NUEVA GUINEA) Vs. Nicaragua. 22 de marzo de 2011(b).

CIDH. Informe No. 73/05. Petición 4534-02. Admisibilidad. Oscar Iván Tabares Toro Vs. Colombia. 13 de octubre de 2005.

CIDH. Informe No. 124/10. Petición 11.990. Admisibilidad. Oscar Orlando Bueno Bonnet y otros Vs. Colombia. 23 de octubre de 2010.

CIDH. Informe No. 103/09. Petición 581-03. Admisibilidad. Richard Conrad Solórzano Contreras Vs. Guatemala. 29 de octubre de 2009.

CIDH. Informe No. 1/11. Petición 295-03. Admisibilidad. Saúl Filormo Cañar Pauta Vs Ecuador.4 de enero de 2011.

CIDH. Informe $\mathrm{N}^{\circ}$ 39/96. Caso 11.673. Inadmisibilidad. Santiago Marzioni Vs Argentina. 15 de octubre de 1996.

CIDH. Informe $\mathrm{N}^{\circ}$ 10/08. Petición 733-03. Admisibilidad. Santos Ernesto Salinas Vs. El Salvador. 5 de marzo de 2008.
CIDH. Informe No. 120/11. Petición 55-05. Inadmisibilidad. Teófilo Sánchez Minaya Vs Perú. 22 de julio de 2011, párr. 28.

CIDH. Informe No. 54/08.Petición 160-02. Admisibilidad. Trabajadores Despedidos del Ministerio de Economía y Finanzas (MEF) Vs. Perú. 24 de julio de 2008.

CIDH. Informe No. 7/08. Petición 1460-06. Admisibilidad. Tyrone Dacosta Cadogan Vs. Barbados. 4 de marzo de 2008.

CIDH. Informe No. 68/10. Petición 10.455. Admisibilidad. Valentín Basto Calderón y otros Vs. Colombia. 12 de julio de 2010.

CIDH. Informe No. 65/08. Petición 460-00. Admisibilidad. Victorio Spoltore Vs. Argentina. 25 de julio de 2008.

CIDH. Informe No. 10/11. Petición 12.329. Admisibilidad.Vicente Ariel Noguera Vs Paraguay. 22 de marzo de 2011(a).

CIDH. Informe $N^{\circ}$ 9/04. Petición 4409/02. Admisibilidad. Walter Huacon Baidal y Mercedes Salazar Cueva Vs. Ecuador. 26 de febrero de 2004.

CIDH. Informe $\mathrm{N}^{\circ}$ 122/01. Petición 15-00. Inadmisibilidad. Wilma Rosa Posadas Vs Argentina. 10 de octubre de 2001.

CIDH. Informe No. 68/09. Petición 16406. Admisibilidad. Wilfredo Quiñonez Barcenas y familia Vs. Colombia. 5 de agosto de 2009. 